\title{
Effect of Heteroatom Concentration in SSZ-13 on the Methanol-to- Olefins Reaction
}

\author{
Mark A. Deimund, ${ }^{\dagger}$ Luke Harrison, ${ }^{\dagger}$ Jonathan D. Lunn, $^{\dagger}$ Yu Liu, ${ }^{\ddagger}$ Andrzej Malek, ${ }^{\ddagger}$ Ramzy Shayib, ${ }^{\S}$ \\ and Mark E. Davis ${ }^{*}{ }^{\dagger}$ \\ ${ }^{\dagger}$ Chemical Engineering, California Institute of Technology, Pasadena, California 91125, United States \\ ¥Olefins, Aromatics, and Alternatives R\&D, The Dow Chemical Company, Freeport, Texas 77541, United States \\ ${ }^{\S}$ Inorganic Materials \& Heterogeneous Catalysis, The Dow Chemical Company, Midland, Michigan 48640, United States
}

\author{
Supporting Information
}

\begin{abstract}
SSZ-13 materials have been synthesized with varying amounts of $\mathrm{Al}$ to produce samples with different concentrations of Brønsted acid sites, and consequently, these SSZ-13 materials contain increasing numbers of paired $\mathrm{Al}$ heteroatoms with increasing $\mathrm{Al}$ content. These materials were then characterized and tested as catalysts for the methanol-toolefins (MTO) reaction at $400{ }^{\circ} \mathrm{C}$ and $100 \%$ methanol conversion under atmospheric pressure. A SAPO-34 sample was also synthesized and tested for comparison. SSZ-13 materials exhibited significant differences in MTO reactivity as $\mathrm{Si} / \mathrm{Al}$ ratios varied. Reduced $\mathrm{Al}$ content (higher $\mathrm{Si} / \mathrm{Al}$ ratio) and, consequently, fewer paired $\mathrm{Al}$ sites led to more stable light olefin selectivities, with a reduced initial transient period, lower initial propane selectivities, and longer catalyst lifetime. To further support the importance of paired $\mathrm{Al}$ sites in the formation of propane during this initial transient period, a series of experiments was conducted wherein an H-SSZ-13 sample was exchanged with $\mathrm{Cu}^{2+}$, steamed, and then back-exchanged to the $\mathrm{H}$ form. The H-SSZ-13 sample exhibited high initial propane selectivity, while the steamed H-SSZ-13, the $\mathrm{Cu}^{2+}$-exchanged SSZ-13 sample, and the steamed Cu-SSZ-13 sample did not, as expected since steaming selectively removes paired $\mathrm{Al}$ sites and $\mathrm{Cu}^{2+}$ exchanges onto these sites. However, when it was back-exchanged to the proton form, the steamed $\mathrm{Cu}-\mathrm{SSZ}-13$ sample still exhibited the high initial alkane selectivity and transient period typical of the higher $\mathrm{Al}$ content materials. This is attributed to protection of paired $\mathrm{Al}$ sites during steaming via the $\mathrm{Cu}^{2+}$ cation. Post-reaction coke analyses reveal that the degree of methylation for each aromatic species increases with increasing Si/Al in SSZ-13. Further, SAPO-34 produces more polycyclic species than SSZ-13 samples. From these data, the paired Al site content appears to be correlated with both MTO reaction behavior and coke species formation in SSZ-13 samples.
\end{abstract}

KEYWORDS: methanol-to-olefins, CHA, zeolite, silicoaluminophosphates, hydrocarbon pool

\section{INTRODUCTION}

The formation of light olefins from methanol provides a commercially feasible route to ethylene and propylene from non-petroleum sources, such as natural gas, coal, and biomass. ${ }^{1-4}$ Microporous aluminosilicate (zeolite) ${ }^{5}$ and silicoaluminophosphate $(\mathrm{SAPO})^{6-9}$ solid acid catalysts are most commonly employed to perform this methanol-to-olefins (MTO) reaction.

Although several zeolite and SAPO framework structures with varying pore sizes and connectivity are capable of performing the MTO reaction (e.g., MFI or *BEA), microporous materials with pore-and-cage systems, such as the chabazite (CHA) topology, are of particular interest. ${ }^{2}$ The reaction proceeds via a "hydrocarbon pool" mechanism, with polymethylaromatic species remaining trapped in the cages as alcohols and linear alkenes flow into and out of these cages via the eight-membered-ring ( $8 \mathrm{MR})$ pores. ${ }^{10-17}$
SAPO-34 and SSZ-13 are two molecular sieves commonly studied for the MTO reaction, both with this CHA topology. SAPO-34, discovered in 1984 at Union Carbide (now UOP), ${ }^{18,19}$ has, in fact, been commercialized for use in the MTO reaction, with light olefin selectivities (ethylene and propylene) of $85-90 \% .^{8,9,20,21}$ SSZ-13, discovered by Zones at Chevron in 1985, is the zeolite analogue of SAPO-34 and can exhibit similar ethylene and propylene selectivities. ${ }^{22,23}$

In each material, Brønsted acid sites catalyze the methanolto-olefins transformation. However, despite the identical crystal structures and use of protons as the catalytic sites, the observed reactivities for SAPO-34 and SSZ-13 are quite different in the MTO reaction, both during reaction and deactivation. ${ }^{23-26}$ In

Received: July 10, 2015

Revised: December 11, 2015

Published: December 22, 2015 
(A)

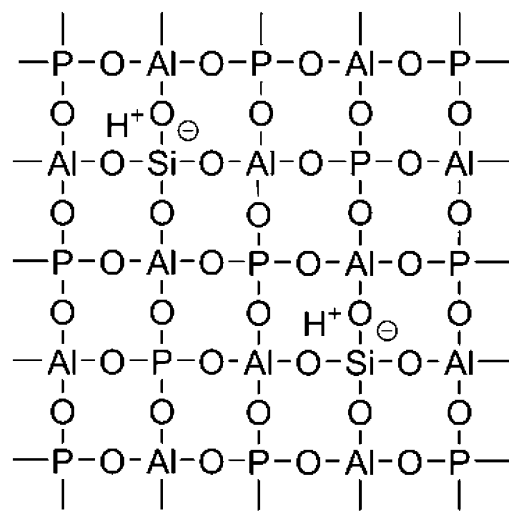

Isolated Si Sites

(B)

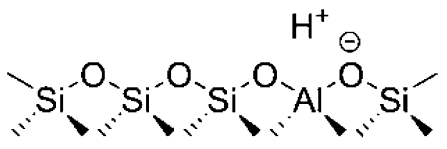

Isolated Al Sites

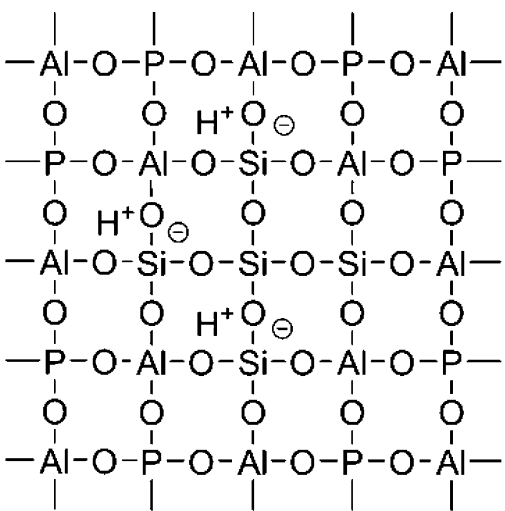

Islanded Si Sites

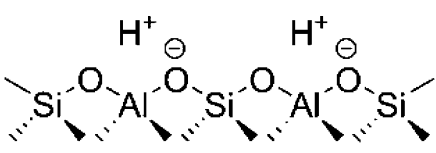

Paired Al Sites

Figure 1. Isolated vs islanded $\mathrm{Si}$ sites in SAPO-34 (A) and isolated vs paired $\mathrm{Al}$ sites in SSZ-13 (B).

comparison to SAPO-34, SSZ-13 typically exhibits differences in light olefin selectivities and higher alkane formation (primarily propane), the magnitudes of which depend on the reaction conditions used. Propane formation is typically associated with the formation of aromatic species within the catalyst pore system. ${ }^{10,11}$ Additionally, SSZ-13 samples with acid site densities comparable to those of SAPO-34 samples tend to deactivate more quickly, forming more (and larger) polycyclic species. $^{25,26}$

This difference in reaction behavior is commonly attributed to disparities in acid site strength between the two materials, ${ }^{26,27}$ with the stronger Brønsted acid sites in SSZ-13 leading to increased reaction rates and therefore increased coking and deactivation. However, acid site density has also been shown to play a role in deactivation time and product selectivity for each CHA-type catalyst. ${ }^{24}$ Increasing $\mathrm{Si} / \mathrm{Al}$ ratios in SSZ-13 samples have been shown to increase catalyst stability and reaction time before deactivation. ${ }^{28}$

To date, the effect of heteroatom concentration (and, accordingly, acid site density/proximity) in these two CHAtype materials has not been well studied to further explore this reactivity difference. In this work, we thus attempt to vary the heteroatom concentration in SSZ-13 to investigate its effect on the selective conversion of methanol to light olefins, in comparison to SAPO-34. Specifically, we wish to investigate whether paired/adjacent Brønsted acid sites within the cages of SSZ-13 may contribute to this observed reactivity difference, particularly during the induction period of SSZ-13. In previous work with SAPO-34 and chabazite samples, Dahl et al. briefly speculated at the possibility of two acid sites interacting within the same CHA cage, but we are not aware of any further followup work to test this hypothesis in detail. ${ }^{24}$

First, we must compare how the requisite Brønsted acid sites may form in each CHA-type material. With SAPO-34, a cation is required to counterbalance the negative charge introduced when $\mathrm{Si}^{4+}$ replaces $\mathrm{P}^{5+}$ in the framework. ${ }^{19}$ For SSZ-13, countercations are required to balance the substitution of $\mathrm{Al}^{3+}$ for $\mathrm{Si}^{4+}$ in the zeolite framework. In as-synthesized materials, these countercations are usually ammonium or alkali-metal cations. After postsynthetic modifications (such as ammonium exchange and calcination), these cations are normally protons, thus giving Brønsted acidity to each material.

Typically in SAPO-34 samples, these Si sites (and thus the associated acid sites) will be isolated (surrounded only by four $\mathrm{Al}$ atoms via oxygen), but syntheses with high Si content may form "islands" of $\mathrm{Si}$ in the sample. ${ }^{17}$ Islanded Si sites in SAPO34 form when, in addition to $\mathrm{Si}$ replacing $\mathrm{P}$ atoms, additional $\mathrm{Si}-\mathrm{O}-\mathrm{Si}$ pairs replace $\mathrm{Al}-\mathrm{O}-\mathrm{P}$ pairs in the framework (resulting in no net addition of framework charge). ${ }^{17,29-32}$ This additional substitution may lead to a large area of $\mathrm{Si}$ atoms bound only to other $\mathrm{Si}$ atoms via oxygen, while the $\mathrm{Si}$ atoms on the edge of this island (bound to other $\mathrm{Al}$ atoms via oxygen) retain their acidity. Si substitution in SAPO frameworks is limited by the inability of the $\mathrm{Si}-\mathrm{O}-\mathrm{P}$ bond structure to form. ${ }^{29}$ Thus, the only bond structures formed through $\mathrm{Si}$ substituting into the framework are $\mathrm{Al}-\mathrm{O}-\mathrm{P}, \mathrm{Si}-\mathrm{O}-\mathrm{Al}$, and $\mathrm{Si}-\mathrm{O}-\mathrm{Si}$.

If Si islanding is present in a SAPO-34 sample, the Brønsted sites around the edge of the island may then be adjacent to one another, and these nearby sites could potentially produce transient activity similar to that observed in SSZ-13 samples.

The presence or absence of Si islanding in SAPO-34 can be investigated both by solid-state ${ }^{29} \mathrm{Si} \mathrm{NMR}$ and by elemental analysis. ${ }^{29} \mathrm{Si}$ NMR reveals the resonances of all $\mathrm{Si}$ sites, $\mathrm{Si}(4 \mathrm{Al})$ through $\mathrm{Si}(0 \mathrm{Al})$ (typically -91 to $-110 \mathrm{ppm}$, respectively). ${ }^{31,32}$ In SAPO-34 samples with $\mathrm{Si}$ islands (both $\mathrm{P}$ and $\mathrm{Al}$ substitutions) all resonances will be present, while samples with isolated $\mathrm{Si}$ sites (only $\mathrm{Si}(4 \mathrm{Al})$ sites) will have only a single NMR resonance from these lone $\mathrm{P}$ substitution sites at either -91 or $-94 \mathrm{ppm}$ for as-made or calcined samples, respectively.

Elemental analysis can also give clues as to whether islanding is present or not in SAPOs. Since isolated Si sites in SAPO-34 
should only replace $\mathrm{P}$ atoms, the $\mathrm{Al}$ mole fraction (for $\mathrm{T}$ atoms only) should be 0.5 , with $\mathrm{Si}$ and $\mathrm{P}$ also summing to 0.5 , making the $(\mathrm{Si}+\mathrm{P}) / \mathrm{Al}$ ratio equal to $1.0 .^{17}$ As the $\mathrm{Si}$ content increases, $\mathrm{Al}$ also begins to be replaced by $\mathrm{Si}$, and the relative fractions change as $\mathrm{Al}$ decreases below 0.5 with the formation of these $\mathrm{Si}$ islands.

Similarly, in the aluminosilicate SSZ-13, due to Loewenstein's rule, ${ }^{33} \mathrm{Al}$ atoms cannot be immediately adjacent to one another (connected only via oxygen atoms), but they may be spaced by a single $\mathrm{Si}$ atom. This separation forms an $\mathrm{Al}-\mathrm{O}-$ $\mathrm{Si}-\mathrm{O}-\mathrm{Al}$ bond, which is known as a "paired site." As the $\mathrm{Si} / \mathrm{Al}$ ratio decreases in SSZ-13 (increasing $\mathrm{Al}$ content), the likelihood of paired $\mathrm{Al}$ sites occurring increases statistically, although there are no simple, direct methods such as solid-state NMR to measure the fraction of paired sites in aluminosilicates. Carefully controlled exchange of a divalent ion onto these SSZ13 samples, with subsequent elemental analysis and comparison of the $\mathrm{M}^{2+} / \mathrm{Al}$ ratio, can, however, serve as one technique to determine the paired site content (and $\mathrm{Al}$ sites close enough in the orientation of the crystal to support a divalent cation) by proxy. By synthesis of SSZ-13s in a wide range of $\mathrm{Si} / \mathrm{Al}$ ratios, the $\mathrm{Al}$ content, and thus the probability of a paired site, can be varied.

Thus, changing the relative amounts of Si for SAPO-34 and of $\mathrm{Al}$ for SSZ-13 in the respective synthesis gels can vary the concentration and type of acid sites within the materials. Figure 1 shows simple diagrams of the isolated, islanded, and paired sites in these materials.

To then study the effect of heteroatom concentration (and accordingly, acid site density/proximity) on the methanol-toolefins reaction in SSZ-13, five SSZ-13 samples with varying Al content were prepared to form samples with varying degrees of isolated acid sites. A SAPO-34 sample with isolated Si sites was also synthesized for characterization and MTO reactivity comparison. Once synthesized, these materials were calcined (SAPO-34) or calcined, ammonium exchanged, and calcined (SSZ-13s) to convert them to their proton forms. To distinguish between isolated and islanded sites (SAPO-34) or isolated and paired sites (SSZ-13), several techniques were employed. For the SAPO-34 material, solid-state ${ }^{29} \mathrm{Si}$ NMR and elemental analysis were performed. For SSZ-13 samples, acid sites were titrated using a $\mathrm{Cu}^{2+}$ exchange procedure, as has been reported by Bates et al. to determine paired/adjacent site content. ${ }^{34}$

All samples were also characterized via powder X-ray diffraction (PXRD), scanning electron microscopy/energy dispersive spectroscopy (SEM/EDS), thermogravimetric analysis (TGA), Ar adsorption, and $\mathrm{NH}_{3}$ temperature-programmed desorption (TPD).

The SAPO-34 sample and the SSZ-13 series then underwent MTO reaction testing in an attempt to discern any differences in reactivity and selectivity, particularly with respect to any transient behavior present for the SSZ-13s.

After reactor tests were completed, the deactivated spent catalysts were dissolved in HF to extract and analyze the occluded organic components.

\section{MATERIALS AND METHODS}

2.1. Synthesis of Microporous Materials. 2.1.1. Isolated Si SAPO-34 Material. The synthesis gel molar composition for the SAPO-34 sample with isolated $\mathrm{Si}$ sites was $1 \mathrm{Al}_{2} \mathrm{O}_{3} / 1 \mathrm{P}_{2} \mathrm{O}_{5} /$ $0.075 \mathrm{SiO}_{2} / 3 \mathrm{TEAOH} / 50 \mathrm{H}_{2} \mathrm{O} .{ }^{17}$ Initially, Catapal $\mathrm{B}$ alumina was dissolved in all the water required before adding Ludox HS-
40 to the mixture as the $\mathrm{Si}$ source. This solution was homogenized, and then 85 wt \% phosphoric acid was added slowly with stirring. Finally, tetraethylammonium hydroxide $(\mathrm{TEAOH})$ was added to the gel and the mixture was stirred until it was homogeneous. The gel mixture was then poured into a Teflon-lined Parr reactor and heated to $200{ }^{\circ} \mathrm{C}$ for $24 \mathrm{~h}$.

2.1.2. SSZ-13 Materials. The desired synthesis gel molar composition of the SSZ-13 samples was of the form $1 \mathrm{SiO}_{2} / x$ $\mathrm{Al}_{2} \mathrm{O}_{3} / 0.2 \mathrm{SDAOH} / 0.2 \mathrm{NaOH} / 40 \mathrm{H}_{2} \mathrm{O}$, where SDAOH is $N, N, N$-trimethyl-1-adamantammonium hydroxide. ${ }^{35}$ The value for $x$ was varied from 0.0052 to 0.078 . In a typical synthesis, Mallinckrodt $\mathrm{NaOH}$ pellets were dissolved in water, and $N, N, N$-trimethyl-1-adamantammonium hydroxide (Sachem, $1.18 \mathrm{mmol}$ of $\mathrm{OH} / \mathrm{g}$ ) was added to this solution. Reheiss F2000 ( 55 wt $\% \mathrm{Al}_{2} \mathrm{O}_{3}$ ) was then added as an alumina source, according to the desired value of $x$, and stirred together until the solution cleared. Finally, fumed silica (Cab-O-Sil M-5) was added, and the gel was stirred until it was homogeneous. The solution was placed in a Teflon-lined Parr reactor and heated in a rotating oven to $160{ }^{\circ} \mathrm{C}$ for approximately 7 days.

2.1.3. Product Recovery. Aliquots of each material were taken periodically by first quenching the Parr reactors in water and then removing enough material for powder X-ray diffraction (PXRD). All materials were recovered by centrifugation. Once the syntheses were completed, each material was washed three times with water and once with acetone before drying in air overnight at $100{ }^{\circ} \mathrm{C}$.

2.2. Calcination, Ammonium Exchange, and Steaming. All materials were calcined in flowing breathing-grade air in a Nabertherm DKN400 muffle furnace. Materials were initially heated to $150{ }^{\circ} \mathrm{C}$ at a heating rate of $1{ }^{\circ} \mathrm{C} / \mathrm{min}$ and held for $3 \mathrm{~h}$ before being heated to $580{ }^{\circ} \mathrm{C}$ (again at a heating rate of $1{ }^{\circ} \mathrm{C} / \mathrm{min}$ ) and held for $12 \mathrm{~h}$ to ensure complete combustion of any remaining organic structure directing agents.

The calcined SSZ-13 materials were then converted to the ammonium form by ion exchanging them three times with $1 \mathrm{M}$ aqueous $\mathrm{NH}_{4} \mathrm{NO}_{3}$ solution at $90^{\circ} \mathrm{C}$ for $2 \mathrm{~h}$. The solid product from each exchange was again recovered by centrifugation, washed with water and acetone, and dried overnight at $100{ }^{\circ} \mathrm{C}$. These SSZ-13 samples were then calcined using the method described above to convert them to the proton form.

Samples in either the $\mathrm{Cu}^{2+}$ or $\mathrm{H}^{+}$form were steamed under atmospheric pressure in an MTI OTF-1200X horizontal tube furnace fitted with a 3 in. mullite tube. Samples were loaded in ceramic calcination boats and placed in the center of the tube furnace. The furnace was ramped at $1{ }^{\circ} \mathrm{C} / \mathrm{min}$ to $750{ }^{\circ} \mathrm{C}$, held at that temperature for $8 \mathrm{~h}$, and then cooled. The entire process was carried out under a flow of moist air that was created by bubbling zero-grade air at $50 \mathrm{~cm}^{3} / \mathrm{min}$ through a heated water saturator (kept at $80{ }^{\circ} \mathrm{C}$ ) upstream of the furnace.

Back-exchange of the steamed Cu-SSZ-13 sample to the proton form was performed at $90{ }^{\circ} \mathrm{C}$ in $0.01 \mathrm{M} \mathrm{HCl}$ for $48 \mathrm{~h}$.

2.3. Characterization. PXRD patterns were obtained with a Rigaku MiniFlex II instrument using $\mathrm{Cu} \mathrm{K} \alpha$ radiation $(\lambda=$ $1.54184 \AA$ A) to determine structure type and purity. Primary crystallite sizes were calculated for each peak using the Scherrer equation with a shape factor of $0.9 .^{36}$ The reported crystallite sizes are the average of the crystallite sizes calculated from each peak. Morphology and elemental composition were also determined via scanning electron microscopy/energy dispersive spectroscopy (SEM/EDS) on a ZEISS 1550VP instrument equipped with an Oxford X-Max SDD energy dispersive X-ray spectrometer. 
Thermogravimetric analysis (TGA) was conducted using a Netzsch STA-449C Jupiter instrument for the SAPO-34 sample and a PerkinElmer STA-6000 instrument for the SSZ-13 materials. The SAPO-34 sample was ramped to $150{ }^{\circ} \mathrm{C}$ at 1 ${ }^{\circ} \mathrm{C} / \mathrm{min}$ and held for $3 \mathrm{~h}$ before ramping to $600{ }^{\circ} \mathrm{C}$ (again at 1 ${ }^{\circ} \mathrm{C} / \mathrm{min}$ ) followed by a final hold for $1 \mathrm{~h}$ at $600{ }^{\circ} \mathrm{C}$. SSZ-13 samples were heated to $900{ }^{\circ} \mathrm{C}$ at a steady ramp rate of $10^{\circ} \mathrm{C} /$ min. Each sample exhibited two distinct mass loss regions, corresponding to water loss and organic loss, with organic mass loss reported as the second region (typically above $250{ }^{\circ} \mathrm{C}$ ).

To determine micropore volume (using the $t$-plot method), Ar adsorption was performed on each sample at $87.45 \mathrm{~K}$ with a Quantachrome Autosorb iQ adsorption instrument using a constant-dose method. Samples were off-gassed at $80{ }^{\circ} \mathrm{C}$ for 1 $\mathrm{h}$, followed by holds for $3 \mathrm{~h}$ at $120{ }^{\circ} \mathrm{C}$ and $10 \mathrm{~h}$ at $350{ }^{\circ} \mathrm{C}$ prior to adsorption measurements.

$\mathrm{NH}_{3}$ temperature-programmed desorption (TPD) experiments were performed on the proton form of each material using an Altamira Instruments AMI-200 apparatus with an online Dymaxion Dycor mass spectrometer to quantify desorbed species. Once they were loaded into the quartz reactor tube, samples were heated to $150{ }^{\circ} \mathrm{C}$ for $1 \mathrm{~h}$ at $10^{\circ} \mathrm{C} /$ min, followed by heating to $600{ }^{\circ} \mathrm{C}$ for $1 \mathrm{~h}$ at $10{ }^{\circ} \mathrm{C} / \mathrm{min}$ in flowing argon $(50 \mathrm{sccm})$ to remove any adsorbed species. Samples were then cooled to $160{ }^{\circ} \mathrm{C}$, and $\mathrm{NH}_{3}$ was dosed onto each sample at a flow rate of $5 \mathrm{sccm}$ in $50 \mathrm{sccm}$ of argon until no further $\mathrm{NH}_{3}$ uptake was observed via the mass spectrometer. After a $2 \mathrm{~h}$ purge in flowing argon $(50 \mathrm{sccm})$ to remove any physisorbed $\mathrm{NH}_{3}$, the sample was heated to $600{ }^{\circ} \mathrm{C}$ at a rate of $10^{\circ} \mathrm{C} / \mathrm{min}$ in $30 \mathrm{sccm}$ argon while the mass spectrometer monitored desorbing products, namely $\mathrm{m} / z 17$ fragments corresponding to $\mathrm{NH}_{3}$. The sample was held at $600{ }^{\circ} \mathrm{C}$ for $2 \mathrm{~h}$ to ensure all species had fully desorbed.

Room-temperature ${ }^{29} \mathrm{Si}$ NMR spectra were obtained on a Bruker Avance $500 \mathrm{MHz}$ spectrometer with a triple-resonance probehead using $4 \mathrm{~mm} \mathrm{ZrO}_{2}$ rotors. The ${ }^{29} \mathrm{Si}$ MAS NMR spectra with high-power proton decoupling were obtained at 99.33 $\mathrm{MHz}$ using a $4.0 \mu \mathrm{s} \pi / 2$ pulse. To allow for experiments with shorter delay times, the samples were evacuated with heating, and $\mathrm{O}_{2}$ was adsorbed into the materials. This allowed usable spectra to be obtained with a delay time of $10 \mathrm{~s}$. The spinning speed was $8 \mathrm{kHz}$, and the chemical shift was referenced to tetrakis(trimethylsilyl)silane (TKTMS).

To determine the number of paired sites present in SSZ-13 samples, the $\mathrm{Cu}^{2+}$ cation was exchanged onto each sample, and the resulting copper content $(\mathrm{Cu} / \mathrm{Al}$ ratio) of each sample was determined via SEM/EDS. Copper cation exchange was performed by liquid-phase ion exchange of a $\mathrm{Cu}\left(\mathrm{NO}_{3}\right)_{2}$ solution (approximately $100 \mathrm{~mL}$ of solution per $1 \mathrm{~g}$ of solids, concentration varied from 0.01 to $0.001 \mathrm{M}$ ) at $25^{\circ} \mathrm{C}$ for $5 \mathrm{~h}^{34}$ The solution $\mathrm{pH}$ was adjusted to 5 using a $0.1 \mathrm{M} \mathrm{NH}_{4} \mathrm{OH}$ solution to prevent formation of $\mathrm{Cu}(\mathrm{OH})_{n}$ species. These carefully controlled exchange conditions allowed for limited $\mathrm{Cu}^{2+}$ uptake onto each sample. The materials were then separated from the $\mathrm{Cu}\left(\mathrm{NO}_{3}\right)_{2}$ solution via centrifugation, washed with distilled water and acetone, and dried.

2.4. MTO Reaction Testing. Catalyst evaluation was carried out in a fixed-bed reactor at ambient pressure. A 200 mg portion of the catalyst (35-60 mesh size) was loaded between layers of $35-60$ mesh quartz chips in a $1 / 4$ in. i.d. $\times 6$ in. stainless steel reactor tube. The methanol flow rate was controlled by an ISCO pump (100DM, Teledyne Technologies Inc.) to achieve a weight hourly space velocity (WHSV) value of $1.3 \mathrm{~h}^{-1}$. The methanol was diluted in $30 \mathrm{sccm}$ of He to a concentration of $10 \%$. The temperature in each experiment was set at $400{ }^{\circ} \mathrm{C}$ and was controlled using a brass heating block around the reactor tube. Prior to the reaction, the catalyst was pretreated at $500{ }^{\circ} \mathrm{C}$ for $2 \mathrm{~h}$ in He. Product evaluation was performed using a Siemens Maxum Process GC instrument. Conversions and selectivities were computed on a carbon mole basis.

2.5. Post-Reaction Catalyst Hydrocarbon Characterization. After the MTO reaction, each catalyst was digested in $\mathrm{HF}$ to recover the encapsulated hydrocarbons, as previously described by Bhawe et al. ${ }^{37}$ Typically, $80 \mathrm{mg}$ of spent catalyst was placed in a $15 \mathrm{~mL}$ polypropylene centrifuge tube, followed by $4 \mathrm{~mL}$ of deionized water and $2 \mathrm{~mL}$ of $48 \%$ aqueous hydrofluoric acid. The powders were stirred in the mixture for approximately $2 \mathrm{~h}$ to allow the framework to fully dissolve. Following dissolution, the organic material was extracted into 2 $\mathrm{mL}$ of deuterated methylene chloride $(2 \times 1 \mathrm{~mL})$.

For gas chromatography/mass spectrometry (GC-MS), 1-4 $\mu \mathrm{L}$ aliquots of the solution were injected into an Agilent $6890 \mathrm{~N}$ GC instrument coupled to a Micromass GCT, SN CA095, TOF GC/MS system operating in the electron impact (EI) mode to obtain the mass spectra. Quantitative analyses were conducted by coupling the GC to an FID detector and matching the corresponding GC/MS results.

${ }^{1} \mathrm{H}$ NMR was conducted on a Varian $400 \mathrm{MHz}$ spectrometer using a standard ${ }^{1} \mathrm{H}$ NMR protocol. UV-vis spectrophotometry was conducted on a Shimadzu UV-2401 spectrophotometer with samples diluted in chloroform (typically 2 drops in $2 \mathrm{~mL}$ ).

\section{RESULTS AND DISCUSSION}

3.1. Characterization. Figure 2 contains the PXRD patterns for the SAPO-34 sample. The PXRD patterns of the

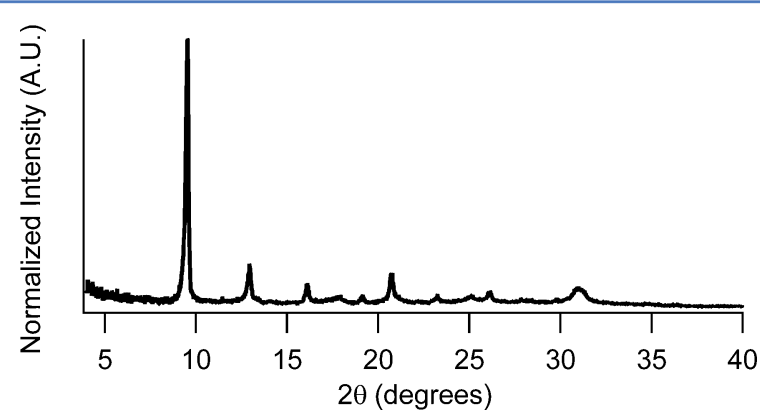

Figure 2. Powder XRD pattern of the proton form of SAPO-34.

proton-form SSZ-13 samples are shown in Figure 3. Additionally, for each material the elemental compositions (by SEM/ EDS), organic content (by TGA), micropore volumes (Ar adsorption), and acid site counts (by $\mathrm{NH}_{3} \mathrm{TPD}$ ) are shown in Table 1 for the SAPO-34 sample and Table 2 for SSZ-13 samples.

As calculated by the Scherrer equation, the SSZ-13 samples (shown in Table 2), have primary crystallite sizes increasing from 0.025 to $0.058 \mu \mathrm{m}$ as $\mathrm{Si} / \mathrm{Al}$ increases from 4.7 to 54.5 for samples SSZ-13A through SSZ-13E, respectively. Larger XRD patterns showing the peak shift (as a result of unit cell size change) with increasing $\mathrm{Al}$ content, as well as some SEM images of samples, are included in the Supporting Information.

Similarly, organic mass losses determined by TGA reveal a trend for the SSZ-13 samples with organic mass loss increasing 


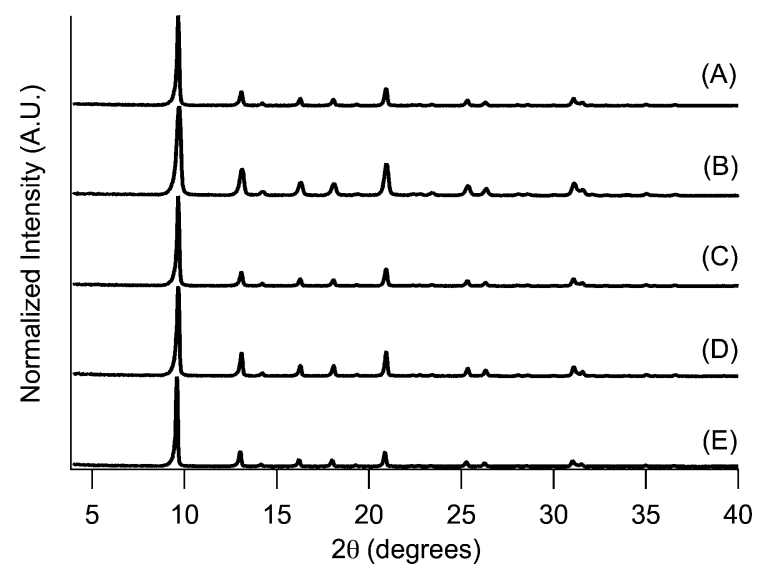

Figure 3. Powder XRD patterns of the proton forms of (A) SSZ-13A, (B) SSZ-13B, (C) SSZ-13C, (D) SSZ-13D, and (E) SSZ-13E.

from $12.6 \%$ to $23.3 \%$ as the $\mathrm{Si} / \mathrm{Al}$ ratio increases, while the SAPO-34 sample has an organic mass loss of approximately $15 \%$.

Micropore volumes for both the SAPO-34 and SSZ-13 samples as determined by Ar adsorption and the $t$-plot method are consistent with the CHA topology.

The $\mathrm{NH}_{3}$ TPDs reveal that, as $\mathrm{Si} / \mathrm{Al}$ increases for each SSZ13 material, the Brønsted acid site count decreases, corresponding to the reduced aluminum content in each sample and in agreement with the elemental $\mathrm{Si} / \mathrm{Al}$ ratios determined. The SAPO-34 sample has a Brønsted acid site density similar to that of SSZ-13A.

The SAPO-34 sample has entirely isolated Si sites, as shown by Figure 4, where only a single resonance is observable, corresponding to the isolated $\mathrm{Si}(4 \mathrm{Al})$ sites.

Elemental analysis corroborates these ${ }^{29} \mathrm{Si}$ solid-state NMR results for the SAPO-34 sample, as the SAPO-34 has an $\mathrm{Al}$ mole fraction of 0.5 and an $(\mathrm{Si}+\mathrm{P}) / \mathrm{Al}$ ratio of 1 , consistent with Si substituting only for P in the SAPO framework and creating only isolated $\mathrm{Si}$ sites.

For the SSZ-13 samples, $\mathrm{Si} / \mathrm{Al}$ ratios from 4.7 to 54.5 were obtained. Paired site fractional probabilities range from approximately 0.25 to 0.025 for this $\mathrm{Si} / \mathrm{Al}$ ratio range, as computed by Bates et al. for $\mathrm{Cu}^{2+}$ uptake in the double-six rings of SSZ-13 samples. ${ }^{38}$ Copper exchange confirms that these paired site values decrease with increasing $\mathrm{Si} / \mathrm{Al}$, as shown in Table 2. As $\mathrm{Si} / \mathrm{Al}$ increases ( $\mathrm{Al}$ content decreases), the fraction of paired $\left(\mathrm{Cu}^{2+}\right.$ exchangeable $) \mathrm{Al}$ sites decreases, with the corresponding fraction of isolated $\mathrm{Al}$ sites increasing. This range of values is sufficient to investigate a wide range of compositions and $\mathrm{Al}$ site proximities for the MTO reaction.

3.2. MTO Reaction Testing. Figure 5 shows the reaction profiles for the SAPO-34 sample. The time on stream (TOS) until deactivation for the SAPO-34 sample was approximately $100 \mathrm{~min}$.

Subsequent $\mathrm{Cu}^{2+}$ exchange performed on this SAPO-34 sample further revealed that no paired acid sites were present in the sample, consistent with the lack of an induction period, in contrast to the SSZ-13 samples. Attempts at synthesizing a SAPO-34 sample with islanded Si species that contained paired Brønsted acid sites (as titrated by $\mathrm{Cu}^{2+}$ exchange) to further investigate this possible effect of paired $\mathrm{Si}$ sites in SAPO-34 were unsuccessful.

Figure 6 illustrates representative time-on-stream reaction data obtained at $400{ }^{\circ} \mathrm{C}$ for the ammonium-exchanged and calcined SSZ-13 samples. Each of the SSZ-13 catalysts is active in producing $\mathrm{C}_{2}-\mathrm{C}_{4}$ olefins when methanol conversion is at or near $100 \%$. As time on stream increases, methanol conversion eventually decreases, with the catalyst longevity differing for each sample. No significant trends in aggregate crystallite size were noted for the SSZ-13 samples. Catalyst lifetimes varied drastically with $\mathrm{Si} / \mathrm{Al}$ ratio for the SSZ-13 samples, with higher $\mathrm{Si} / \mathrm{Al}$ ratios having the longest lifetimes and most stable olefin selectivities, as also noted by Zhu et al. ${ }^{28}$ and Dahl et al. ${ }^{24}$

Light alkanes, mainly propane, are observed among the products at the start of the reaction for all of the SSZ-13s, with selectivities to these alkanes decreasing with time on stream. Samples with lower $\mathrm{Si} / \mathrm{Al}$ ratios (and consequently, higher paired site content from Table 2) exhibit higher initial selectivities to these transient light alkane products. Additionally, as the $\mathrm{Si} / \mathrm{Al}$ ratio increases for the SSZ-13 samples, the crossover point where ethylene selectivity surpasses propylene selectivity occurs at decreasing TOS values. Both of these observations in the transient behavior of SSZ-13 suggest that, mechanistically, the MTO reaction in CHA is being affected by the acid site concentration (and proximity), thus producing the differing selectivities to alkanes and light olefins observed.

Interestingly, as the $\mathrm{Si} / \mathrm{Al}$ ratio increases, the SSZ-13 samples begin to resemble SAPO-34 in their reactivity. In fact, the activities of SSZ-13 samples with the highest $\mathrm{Si} / \mathrm{Al}$ ratios tend to resemble that of the SAPO-34 sample, in both total light olefin selectivities and catalyst lifetime. The key difference observed is the higher ethylene selectivity in the SSZ-13 samples, in comparison to the higher propylene selectivity for the SAPO-34 sample shown here, although ethylene selectivity in SAPO-34s has been reported to increase relative to propylene with sufficient time on stream. ${ }^{25,39}$ Additionally, it is worth remembering that SSZ-13 and SAPO-34, while both having the CHA topology, are two different types of materials-zeolite and SAPO, respectively. This similarity in reactivity between SSZ-13 and SAPO-34 could be due to the increasing isolation of $\mathrm{Al}$ sites in higher $\mathrm{Si} / \mathrm{Al} \mathrm{SSZ-13s,}$ analogous to the more isolated Brønsted acid sites in the SAPO-34s.

Under the tested reaction conditions (i.e., complete methanol and DME conversion), the dehydration of methanol produces a significant amount of water, which restricts the formation of Lewis acid sites in these catalysts. Thus, we have not attempted to characterize Lewis acid sites in these materials prior to their introduction into the reactor.

The amount of organic residue measured by TGA in the spent samples, as shown in Tables 1 and 2 , increases with

Table 1. SAPO-34 Characterization Data

\begin{tabular}{|c|c|c|c|c|c|c|c|c|c|}
\hline material & $\begin{array}{l}\text { synthesis gel } \\
\mathrm{SiO}_{2} x \text { value }\end{array}$ & $\begin{array}{l}\text { Si mole } \\
\text { fraction }\end{array}$ & $\begin{array}{l}\mathrm{P} \text { mole } \\
\text { fraction }\end{array}$ & $\begin{array}{l}\text { Al mole } \\
\text { fraction }\end{array}$ & $\begin{array}{l}(\mathrm{Si}+\mathrm{P}) / \mathrm{Al} \\
\text { molar ratio }\end{array}$ & $\begin{array}{c}\text { primary } \\
\text { crystallite size } \\
(\mu \mathrm{m})\end{array}$ & $\begin{array}{c}\text { organic mass loss } \\
(\%, \text { TGA })\end{array}$ & $\begin{array}{c}\text { micropore } \\
\text { volume }\left(\mathrm{cm}^{3} / \mathrm{g}\right)\end{array}$ & $\begin{array}{l}\text { acid site density by } \\
\mathrm{NH}_{3}(\mathrm{mmol} / \mathrm{g})\end{array}$ \\
\hline $\begin{array}{c}\text { SAPO- } \\
34\end{array}$ & 0.075 & 0.06 & 0.44 & 0.50 & 1.00 & 0.035 & 15.1 & 0.21 & 0.63 \\
\hline
\end{tabular}


Table 2. SSZ-13 Characterization Data

\begin{tabular}{|c|c|c|c|c|c|c|c|}
\hline material & $\begin{array}{c}\text { synthesis gel } \mathrm{Al}_{2} \mathrm{O}_{3} \\
x \text { value }\end{array}$ & $\mathrm{Si} / \mathrm{Al}$ & $\begin{array}{l}\text { primary crystallite size } \\
(\mu \mathrm{m})\end{array}$ & $\begin{array}{l}\text { organic mass loss } \\
(\%, \text { TGA })\end{array}$ & $\begin{array}{l}\text { micropore volume } \\
\left(\mathrm{cm}^{3} / \mathrm{g}\right)\end{array}$ & $\begin{array}{l}\text { acid site density by } \mathrm{NH}_{3} \\
(\mathrm{mmol} / \mathrm{g})\end{array}$ & $\begin{array}{l}\mathrm{Cu} / \mathrm{Al} \text { molar } \\
\text { ratio }\end{array}$ \\
\hline SSZ-13A & 0.078 & 4.7 & 0.025 & 12.6 & & 0.65 & 0.19 \\
\hline SSZ-13B & 0.026 & 17.0 & 0.034 & 19.6 & & 0.49 & 0.08 \\
\hline $\begin{array}{l}\text { SSZ- } \\
13 \mathrm{C}\end{array}$ & 0.0156 & 21.2 & 0.049 & 21.9 & 0.23 & 0.47 & 0.06 \\
\hline $\begin{array}{l}\text { SSZ- } \\
13 \mathrm{D}\end{array}$ & 0.0078 & 45.9 & 0.055 & 22.5 & & 0.26 & 0.03 \\
\hline SSZ-13E & 0.0052 & 54.5 & 0.058 & 23.3 & 0.21 & 0.18 & \\
\hline
\end{tabular}

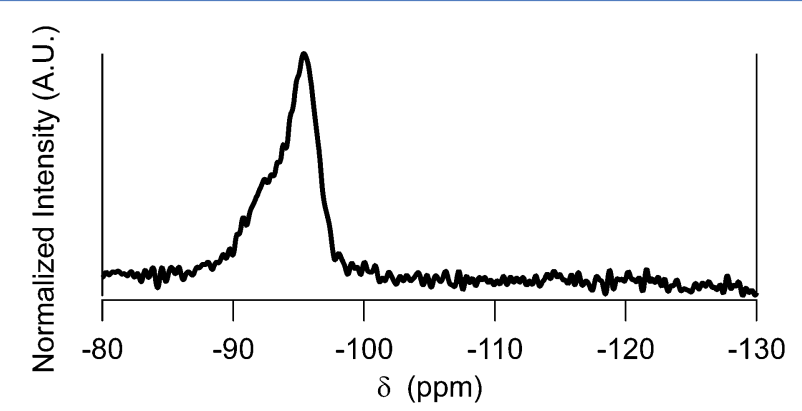

Figure 4. ${ }^{29} \mathrm{Si}$ NMR spectrum for calcined SAPO-34.

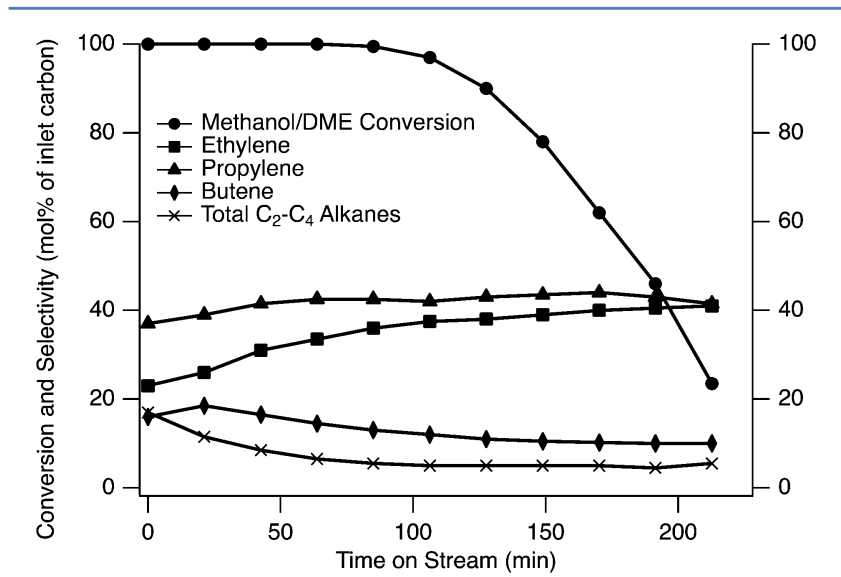

Figure 5. Representative MTO reaction data obtained at $400{ }^{\circ} \mathrm{C}$ for the calcined SAPO- 34 .

increasing $\mathrm{Si} / \mathrm{Al}$ ratios of the SSZ-13 samples. The rapid deactivation of samples with the lowest $\mathrm{Si} / \mathrm{Al}$ ratios results in less overall residue, indicating deactivation by acid site blocking and consistent with coke formation proportional to the amount of methanol fed to the samples. ${ }^{40}$

If the initial propane selectivities (symptomatic of aromatic species formation within the catalysts) are overlaid with the theoretical paired $\mathrm{Al}$ site content as a function of $\mathrm{Si} / \mathrm{Al}$ ratio for each sample, as shown in Figure 7, we observe that they each exhibit a similar decreasing trend with increasing framework $\mathrm{Si}$ / $\mathrm{Al}$ ratio. Additionally, $\mathrm{Cu} / \mathrm{Al}$ ratios obtained for the samples match well with the theoretical values for paired framework Al sites.

To further prove the importance of paired $\mathrm{Al}$ sites in the formation of propane during this initial transient period for SSZ-13, a final series of experiments was conducted wherein an H-SSZ-13 sample $(\mathrm{Si} / \mathrm{Al}=13)$ was exchanged with $\mathrm{Cu}^{2+}$, steamed, and then back-exchanged to the $\mathrm{H}$ form.

If paired $\mathrm{Al}$ sites are crucial to the initial propane formation and transient period observed in SSZ-13, we should then expect that the initial H-SSZ-13 sample exhibits high initial propane selectivity in the MTO reaction, while the $\mathrm{Cu}^{2+}$-exchanged SSZ-13 sample should not, as the $\mathrm{Cu}^{2+}$ ions can partially block the paired $\mathrm{Al}$ sites. Further, the steamed $\mathrm{H}-\mathrm{SSZ}-13$ and $\mathrm{Cu}-$ SSZ-13 samples should not exhibit significant initial propane selectivity or a transient period, since steaming selectively removes these paired $\mathrm{Al}$ sites. ${ }^{41}$

Finally, the steamed Cu-SSZ-13 sample can be backexchanged to the $\mathrm{H}$ form. During the steaming process, the $\mathrm{Cu}^{2+}$ cation may help protect the paired $\mathrm{Al}$ sites from hydrolysis and, if some of these paired sites are intact and responsible for the transience we observe, we should then expect to see a return of this transient period and high initial propane selectivity for this back-exchanged sample when tested in the MTO reaction.

Table 3 shows the initial alkane selectivities for each sample. The changes in initial alkane formation are as expected after the $\mathrm{Cu}^{2+}$ exchange, steaming, and proton back-exchange procedures. Reaction conditions were slightly different in this series of experiments to enhance the effect of the $\mathrm{Cu}^{2+}$ exchange and steaming experiments on alkane selectivity.

3.3. Post-Reaction Characterization Results. Upon completion of the MTO reaction tests, the catalysts were dissolved in $\mathrm{HF}$ and the extracted hydrocarbon pool solutions were analyzed by ${ }^{1} \mathrm{H}$ NMR, UV-vis, and GC-MS. While we have not attempted to quantify the absolute amounts of hydrocarbons recovered, it was apparent that the hydrocarbon concentrations were lowest for the samples with the lowest $\mathrm{Si}$ / $\mathrm{Al}$ (i.e., SSZ-13A).

Figure 8 shows the distribution of occluded organic species obtained from the GC-MS analysis. SAPO-34 shows a very clear trend of increasing aromatic rings with the highest concentration in pyrenes (the largest molecule that can fit in the CHA cage). In fact, $46 \%$ of the hydrocarbon from SAPO- 34 was pyrene. The SSZ-13 samples show a different pattern, however, with the majority of the species concentrated in the naphthalenes and trailing off with 3- and 4- ring aromatics. An interesting trend in the SSZ-13 samples is the different and increasing amounts of alkylated benzenes with increasing $\mathrm{Si} / \mathrm{Al}$. The distribution within the benzene species shows that, in each material, tetramethylbenzene was the primary species present. Although the total naphthalenes fractions are similar in all of the SSZ-13 samples, the highest $\mathrm{Si} / \mathrm{Al}$ values show a tendency for higher alkylated species while the low $\mathrm{Si} / \mathrm{Al}$ values show almost only naphthalene. The anthracene/phenanthrene and pyrene fractions are mainly unalkylated in all samples.

Figures 9 and 10 show the ${ }^{1} \mathrm{H}$ NMR and UV-vis data for the extracted hydrocarbon solutions. The ${ }^{1} \mathrm{H}$ NMR data illustrate features consistent with the GC-MS results. The most discernible species are naphthalene (7.85 and $7.45 \mathrm{ppm})$ that are observed from SSZ-13A-C and the pyrene proton peaks shown between 8 and 8.25 ppm for SAPO-34 and SSZ-13B,C. As with the GC-MS data, pyrene appears as the dominant 

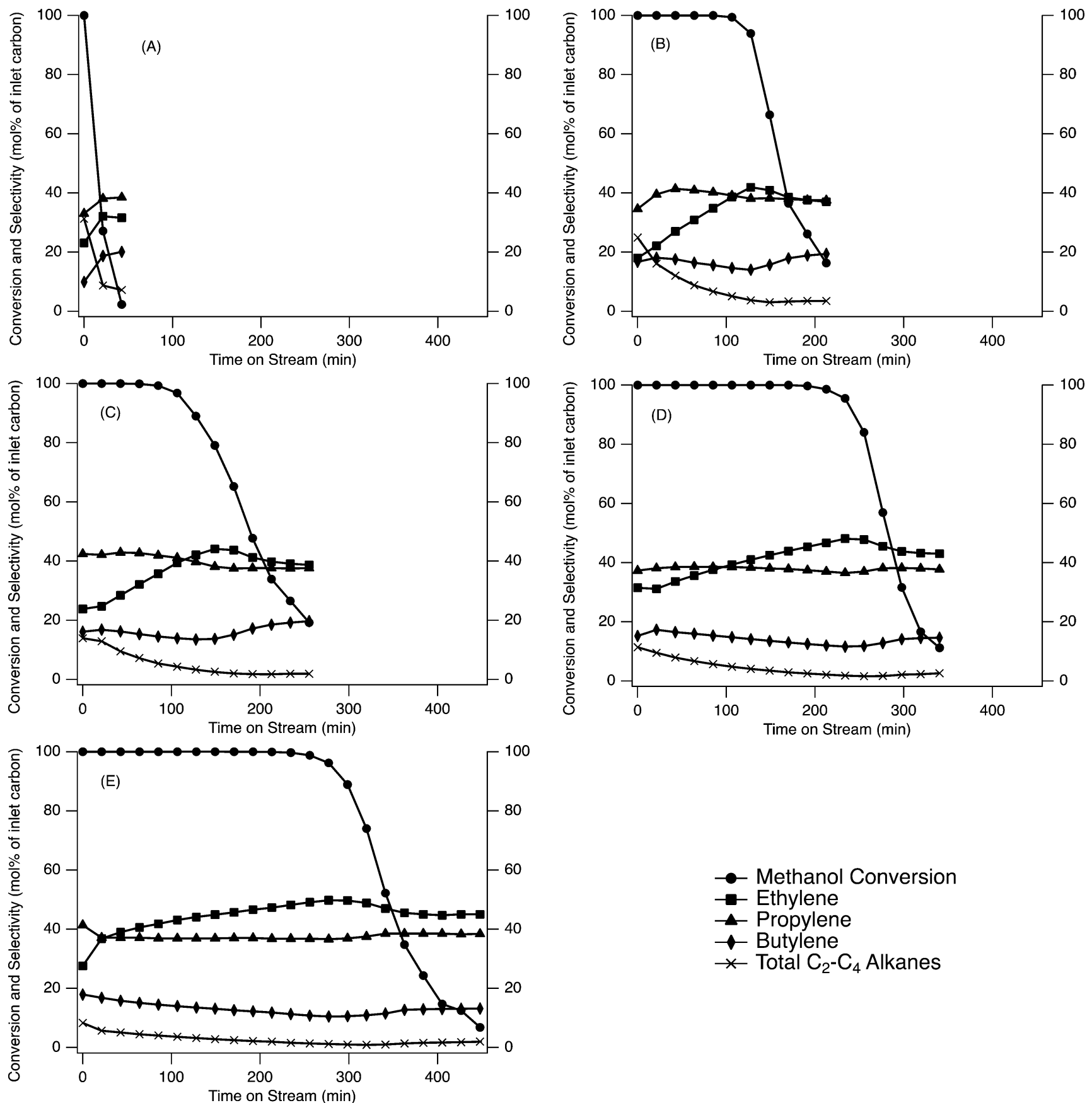

Figure 6. Representative MTO reaction data obtained at $400{ }^{\circ} \mathrm{C}$ for the ammonium-exchanged and calcined (A) SSZ-13A, (B) SSZ-13B, (C) SSZ13C, (D) SSZ-13D, and (E) SSZ-13E.

species in SAPO-34, naphthalene in SSZ-13A, and more of a mixture for SSZ-13B,C. The alkane regions are also consistent, showing increasing nonaromatic protons for SSZ-13B,C.

The UV-vis spectra of the extracted samples (Figure 10) show bands characteristic of benzenes, naphthalenes, anthracenes/phenanthrenes, and pyrenes. The SAPO-34 solution is dominated by the various pyrene absorbance bands. While pyrene can be seen in the SSZ-13 materials as well, it is clear that the bulk of absorbance shifts to lower wavenumbers for the higher $\mathrm{Si} / \mathrm{Al}$, consistent with the finding of higher naphthalenes and increased alkylated benzene content of those solutions.

These differences between SAPO-34 and SSZ-13 occluded products likely result from the varied framework compositions and nature of the acid sites in each material. Acid site proximity in each material is a potential source of this difference.

\section{CONCLUSION}

SSZ-13 samples were synthesized in a wide range of $\mathrm{Si} / \mathrm{Al}$ ratios, with several trends appearing. As $\mathrm{Si} / \mathrm{Al}$ increased, primary crystallite size and organic mass loss (by TGA) increased, while Brønsted acid site density (by $\mathrm{NH}_{3} \mathrm{TPD}$ ) and paired $\mathrm{Al}$ site content (by $\mathrm{Cu}^{2+}$ exchange and SEM/EDS) decreased. A SAPO-34 sample with isolated Brønsted acid sites was also synthesized for comparison to these samples. No paired sites were titrated by $\mathrm{Cu}^{2+}$ exchange in this SAPO-34 sample. 


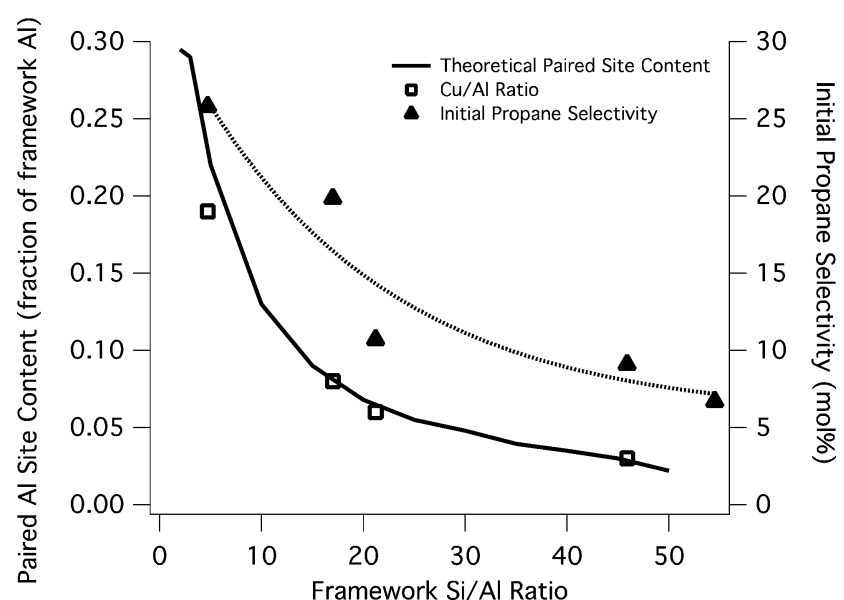

Figure 7. Paired $\mathrm{Al}$ site content and initial propane selectivity as a function of $\mathrm{Si} / \mathrm{Al}$ ratio. The theoretical line is from Bates et al. ${ }^{38}$

Table 3. Initial Alkane Selectivities (\%) for SSZ-13s

\begin{tabular}{|lccc}
\hline & unsteamed & steamed & back-exchanged to $\mathrm{H}$ form \\
\hline $\mathrm{H}$ form & 45 & 5 & \\
$\mathrm{Cu}$ form & 30 & 7 & 13 \\
\hline
\end{tabular}

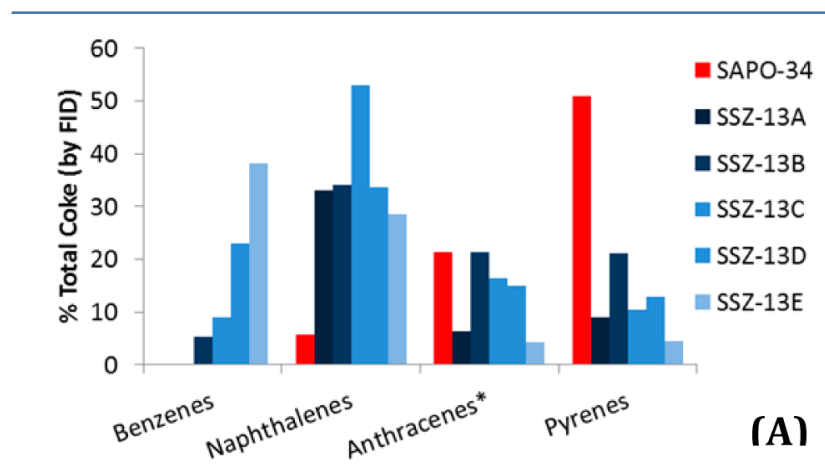
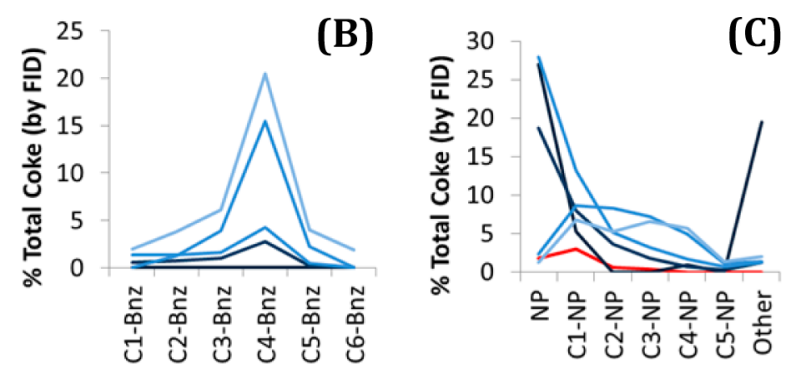

Figure 8. GC-MS distribution of extracted hydrocarbon species grouped by ring number/type (A) and also categorized into alkylbenzenes (B) and naphthalenes (C). Legend: Bnz, benzene; NP, naphthalene; Other, non-naphthalene 2-ring species; Anthracenes*, includes phenanthrenes.

Furthermore, as the $\mathrm{Si} / \mathrm{Al}$ ratio of the $\mathrm{SSZ}-13$ s varied, the MTO reactivity changed markedly. For lower Si/Al materials, drastically shorter catalytic lifetimes and significant transient light alkane selectivities were observed. Increasing $\mathrm{Si} / \mathrm{Al}$ of the SSZ-13 samples reduced these transient selectivities. In fact, as the $\mathrm{Si} / \mathrm{Al}$ ratios of the SSZ-13 samples increased, the MTO product selectivities began to resemble those observed for the SAPO-34 sample. This difference in reactivity among the SSZ-

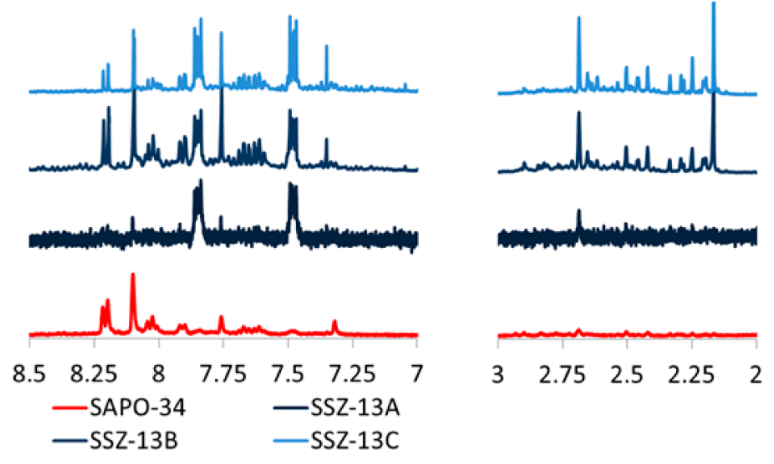

Figure 9. ${ }^{1} \mathrm{H}$ NMR of the extracted hydrocarbon solutions showing the aromatic and alkyl regions. The NMR data are normalized to show similar maximum intensities between samples to facilitate comparison.

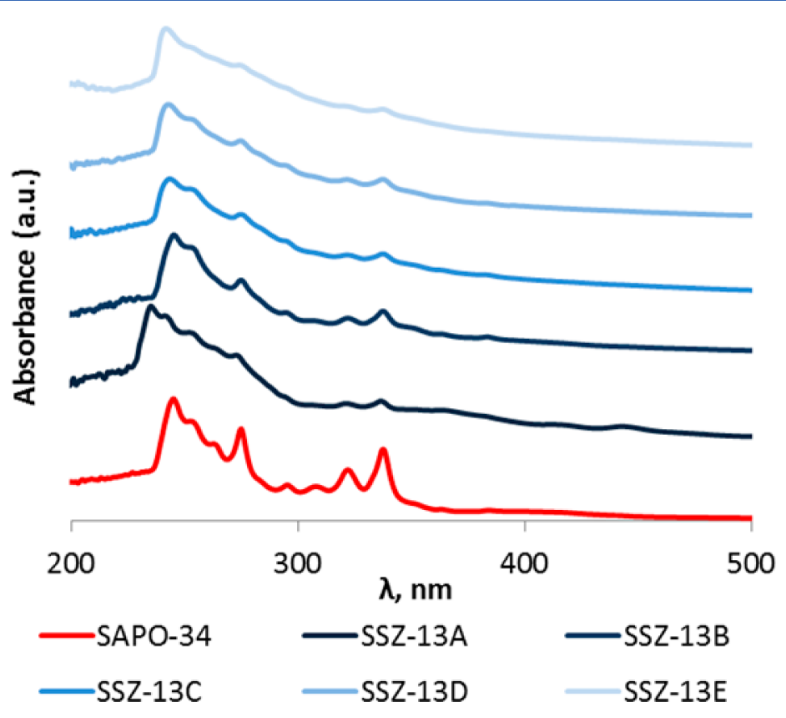

Figure 10. UV-vis spectra of the extracted hydrocarbon solutions. To facilitate comparison, the spectra are normalized such that the absorbances at $243 \mathrm{~nm}$ are equal.

13 samples could be attributed to the decreasing paired $\mathrm{Al}$ site content as the $\mathrm{Si} / \mathrm{Al}$ ratio increases.

While catalytic tests show similar product distributions for SAPO-34 and SSZ-13 samples with the highest Si/Al ratios, the distribution of hydrocarbon pool species is significantly different for the two framework compositions. SAPO-34 shows a clear tendency to form polyaromatics to the limit of the CHA cage size (pyrenes). SSZ-13, on the other hand, shows a tendency to form smaller aromatic species, mainly naphthalenes and alkylbenzenes. The concentration of alkylbenzenes is the lowest for the samples with the highest concentration of paired aluminum sites; the ratio of alkylbenzenes to multiring aromatics is consistent with observed propane selectivity and hence the aromatization activity.

In conclusion, SSZ-13 samples with a higher probability for having paired acid sites (lower $\mathrm{Si} / \mathrm{Al}$ ratios) have very different MTO reactivities in comparison to materials with a high probability of having only isolated acid sites (higher $\mathrm{Si} / \mathrm{Al}$ ratios). This is best illustrated in the quicker deactivation times and initial transient product selectivities for the lower $\mathrm{Si} / \mathrm{Al}$ ratio materials, and this behavior is likely due to interaction among the reacting species at the paired $\mathrm{Al}$ sites in these samples. 


\section{ASSOCIATED CONTENT}

\section{S Supporting Information}

The Supporting Information is available free of charge on the ACS Publications website at DOI: 10.1021/acscatal.5b01450.

Additional characterization and MTO reaction data (PDF)

\section{AUTHOR INFORMATION}

\section{Corresponding Author}

*E-mail for M.E.D.: mdavis@cheme.caltech.edu.

\section{Notes}

The authors declare no competing financial interest.

\section{ACKNOWLEDGMENTS}

The authors thank The Dow Chemical Company for financial support of this project. The authors also thank Cassie Fhaner for analytical work associated with the GC-MS data.

\section{REFERENCES}

(1) Vora, B.; Chen, J. Q.; Bozzano, A.; Glover, B.; Barger, P. Catal. Today 2009, 141, 77-83.

(2) Olsbye, U.; Svelle, S.; Bjørgen, M.; Beato, P.; Janssens, T. V. W.; Joensen, F.; Bordiga, S.; Lillerud, K. P. Angew. Chem., Int. Ed. 2012, 51, $5810-5831$.

(3) Ilias, S.; Bhan, A. ACS Catal. 2013, 3, 18-31.

(4) Stocker, M. Microporous Mesoporous Mater. 1999, 29, 3-48.

(5) Froment, G. F.; Dehertog, W. J. H.; Marchi, A. J., In Catalysis; Spivey, J. J., Ed.; The Royal Society of Chemistry: Cambridge, U.K., 1992; Vol. 9, pp 1-64.

(6) Dai, W.; Wang, X.; Wu, G.; Guan, N.; Hunger, M.; Li, L. ACS Catal. 2011, 1, 292-299.

(7) Kaiser, S. W. Using silicoaluminophosphate molecular sieve catalyst. U.S. Patent 4,499,327. 1985.

(8) Tian, P.; Wei, Y.; Ye, M.; Liu, Z. ACS Catal. 2015, 5, 1922-1938.

(9) Chen, J. Q.; Bozzano, A.; Glover, B.; Fuglerud, T.; Kvisle, S. Catal. Today 2005, 106, 103-107.

(10) Dahl, I. M.; Kolboe, S. J. Catal. 1994, 149, 458-464.

(11) Dahl, I. M.; Kolboe, S. J. Catal. 1996, 161, 304-309.

(12) Olsbye, U.; Bjørgen, M.; Svelle, S.; Lillerud, K.-P.; Kolboe, S. Catal. Today 2005, 106, 108-111.

(13) Haw, J. F.; Marcus, D. M. Top. Catal. 2005, 34, 41-48.

(14) Arstad, B.; Nicholas, J. B.; Haw, J. F. J. Am. Chem. Soc. 2004, 126, 2991-3001.

(15) Zhu, Q.; Kondo, J. N.; Ohnuma, R.; Kubota, Y.; Yamaguchi, M.; Tatsumi, T. Microporous Mesoporous Mater. 2008, 112, 153-161.

(16) Schulz, H. Catal. Today 2010, 154, 183-194.

(17) Xu, L.; Du, A.; Wei, Y.; Wang, Y.; Yu, Z.; He, Y.; Zhang, X.; Liu, Z. Microporous Mesoporous Mater. 2008, 115, 332-337.

(18) Lok, B. M.; Messina, C. A.; Patton, R. L.; Gajek, R. T.; Cannan, T. R.; Flanigen, E. M. J. Am. Chem. Soc. 1984, 106, 6092-6093.

(19) Lok, B. M.; Messina, C. A.; Patton, R. L.; Gajek, R. T.; Cannan, T. R.; Flanigen, E. M. U.S. Patent 4,440,871, April 3, 1984.

(20) Liang, J.; Li, H.; Zhao, S.; Guo, W.; Wang, R.; Ying, M. Appl. Catal. 1990, 64, 31-40.

(21) Vora, B. V.; Marker, T. L.; Barger, P. T.; Nilsen, H. R.; Kvisle, S.; Fuglerud, T. Stud. Surf. Sci. Catal. 1997, 107, 87-98.

(22) Zones, S. I., Zeolite SSZ-13 and its method of preparation; U.S. Patent 4,544,538, 1985.

(23) Yuen, L.-T.; Zones, S. I.; Harris, T. V.; Gallegos, E. J.; Auroux, A. Microporous Mater. 1994, 2, 105-117.

(24) Dahl, I. M.; Mostad, H.; Akporiaye, D.; Wendelbo, R. Microporous Mesoporous Mater. 1999, 29, 185-190.

(25) Barger, P. In Zeolites for Cleaner Technologies; Guisnet, M., Gilson, J.-P., Eds.; Imperial College Press: London, 2002; Vol. 3, pp 239-260.
(26) Bleken, F.; Bjørgen, M.; Palumbo, L.; Bordiga, S.; Svelle, S.; Lillerud, K.-P.; Olsbye, U. Top. Catal. 2009, 52, 218-228.

(27) Guisnet, M.; Costa, L.; Ribiero, F. R. J. Mol. Catal. A: Chem. 2009, 305, 69-83.

(28) Zhu, Q.; Kondo, J. N.; Ohnuma, R.; Kubota, Y.; Yamaguchi, M.; Tatsumi, T. Microporous Mesoporous Mater. 2008, 112, 153-161.

(29) Ashtekar, S.; Chilukuri, S. V. V; Chakrabarty, D. K. J. Phys. Chem. 1994, 98, 4878-4883.

(30) Zibrowius, B.; Loffler, E.; Hunger, M. Zeolites 1992, 12, 167174.

(31) Vomscheid, R.; Briend, M.; Peltre, M. J.; Massiani, P.; Man, P. P.; Barthomeuf, D. J. Chem. Soc., Chem. Commun. 1993, 544-546.

(32) Tan, J.; Liu, Z.; Bao, X.; Liu, X.; Han, X.; He, C.; Zhai, R. Microporous Mesoporous Mater. 2002, 53, 97-108.

(33) Loewenstein, W. Am. Mineral. 1954, 39, 92-96.

(34) Bates, S. A.; Delgass, W. N.; Ribeiro, F. H.; Miller, J. T.; Gounder, R. J. Catal. 2014, 312, 26-36.

(35) Yuen, L. T.; Zones, S. I. In Verified Synthesis of Zeolitic Materials, 2nd ed.; Robson, H., Ed.; Elsevier: Amsterdam, 2001; pp 126-128.

(36) Burton, A. W.; Ong, K.; Rea, T.; Chan, I. Y. Microporous Mesoporous Mater. 2009, 117, 75-90.

(37) Bhawe, Y.; Moliner-Marin, M.; Lunn, J. D.; Liu, Y.; Malek, A.; Davis, M. ACS Catal. 2012, 2, 2490-2495.

(38) Bates, S. A.; Verma, A. A.; Paolucci, C.; Parekh, A. A.; Anggara, T.; Yezerets, A.; Schneider, W. F.; Miller, J. T.; Delgass, W. N.; Ribeiro, F. H. J. Catal. 2014, 312, 87-97.

(39) Song, W. G.; Fu, H.; Haw, J. F. J. Am. Chem. Soc. 2001, 123, $4749-4754$.

(40) Chen, D.; Rebo, H. P.; Grønvold, A.; Moljord, K.; Holmen, A. Microporous Mesoporous Mater. 2000, 35-36, 121-135.

(41) Lago, R. M.; Haag, W. O.; Mikovsky, R. J.; Olson, D. H.; Hellring, S. D.; Schmitt, K. D.; Kerr, G. T. Stud. Surf. Sci. Catal. 1986, $28,677-684$. 